\title{
Sleep in brain development
}

\author{
PATRICIO D. PEIRANO and CECILIA R. ALGARÍN
}

Laboratorio de Sueño y Neurobiología Funcional, INTA, Universidad de Chile, Santiago, Chile.

\begin{abstract}
With the discovery of rapid eye movement (REM) sleep, sleep was no longer considered a homogeneous state of passive rest for the brain. On the contrary, sleep, and especially REM sleep, appeared as an active condition of intense cerebral activity. The fact that we get large amounts of sleep in early life suggested that sleep may play a role in brain maturation. This idea has been investigated for many years through a large number of animal and human studies, but evidence remains fragmented. The hypothesis proposed was that REM sleep would provide an endogenous source of activation, possibly critical for structural maturation of the central nervous system. This proposal led to a series of experiments looking at the role of REM sleep in brain development. In particular, the influence of sleep in developing the visual system has been highlighted. More recently, non-REM (NREM) sleep state has become a major focus of attention. The current data underscore the importance of both REM sleep and NREM sleep states in normal synaptic development and lend support to their functional roles in brain maturation. Both sleep states appear to be important for neuronal development, but the corresponding contribution is likely to be different.
\end{abstract}

Key terms: sleep development, brain development, brain plasticity, NREM sleep, REM sleep,

\section{Introducing sleep}

Sleep is usually considered a resting state. In reality, this conception does not necessarily agree with some of the physiological processes during sleep. Neurons in most parts of the brain remain active during sleep and the brain expends much energy with this neural activity during sleep. It is easy to conceive that neurons responsible for autonomic functions such as respiration remain active in both sleep and waking, but neurons in other parts of the brain also remain active, often in a highly synchronous and rhythmic manner (Steriade, 2006).

Studies in humans half a century ago first demonstrated that sleep occurs in two distinct states: rapid eye movement (REM) sleep and non-REM (NREM) sleep (Aserinski and Kleitman, 1953). These sleep states exist in human fetuses and newborns, although their earliest age of appearance is controversial (Curzi-
Dascalova et al., 1988; Curzi-Dascalova and Challamel, 2000; Mirmiran et al., 2003a; Peirano et al., 2003). Studies using chronically catheterized fetal animals and imaging of the human fetus have emphasized the similarities between fetal and postnatal sleep states (Richardson et al., 1994; Morrison et al., 1997; Czikk et al., 2001; Czikk et al., 2002; Morrison et al., 2005). The current concept regarding REM sleep is that there is a controlling network composed of several areas of the forebrain and that brainstem structures may be responsible for its final expression (Pace-Schott and Hobson, 2002; McCarley, 2007). With respect to the development of NREM sleep, it also requires the establishment of a specific network of excitatory and inhibitory neural components, that includes the formation of thalamocortical and intracortical patterns of innervation (Curzi-Dascalova and Challamel, 2000; Pace-Schott and Hobson, 2002; McCarley, 2007).

Corresponding Author: Patricio Peirano, MD, PhD, Laboratorio de Sueño y Neurobiología Funcional, INTA, Universidad de Chile, Av. Macul 5540, Casilla (P.O. Box) 138-11, Santiago, Chile, Telephone: (56-2) 978-1447, Fax: (56-2) 221-4030, E-mail: ppeirano@inta.cl 
Based on data from animals with prenatal brain development (sheep, for instance), there is evidence for prenatal sleep states development (Richardson et al., 1994; Morrison et al., 1997; Czikk et al., 2001; Czikk et al., 2002; Morrison et al., 2005). Of note, (i) regional blood flow within the brain increases during REM sleep, especially in areas thought to be involved with the generation of this sleep state (Czikk et al., 2001), (ii) cerebral leucine metabolism correlates to sleep states (Czikk et al., 2002), suggesting that protein synthesis and degradation processes within the brain are modified by them, and (iii) cerebral blood flow and oxygen delivery are higher during spontaneous and carbachol-induced REM sleep relative to spontaneous and scopolamine-induced NREM sleep (Morrison et al., 2005), indicating that pharmacologic manipulation induced fetal sleep states behaviorally, electrophysiologically and metabolically. In addition, in newborn lambs, the cerebral metabolic rate of oxygen consumption is as high during REM sleep as during wakefulness (Silvani et al., 2006). As a whole, these studies emphasize that comparisons of fetal and adult sleep states in developmental profile and pharmacological responses may be species specific (Morrison et al., 1997).

Regarding human sleep ontogeny, physiological and behavioral parameters that characterize REM sleep are present well before the normal term age (CurziDascalova et al., 1988; Curzi-Dascalova and Challamel, 2000). There is also evidence showing that REM sleep may be more accurately described as having phasic and tonic stages (Shimohira et al., 2002); furthermore, these REM sleep patterns demonstrate consistent results on a nightby-night basis (Kimura et al., 2001). This distinction within REM sleep may contribute to the more appropriate interpretation of sleep differences between species with prenatal and postnatal brain development (Peirano et al., 2003).

The above mentioned considerations could be particularly relevant while considering that the last decades have witnessed a renewed interest in the study of the role of sleep in two main manifestations of brain plasticity: brain development on the one hand, and learning and memory, on the other hand (see Maquet et al., 2003; Frank and Heller, 2006).

\section{Development of sleep}

Fetal movements are interspersed with periods of quiescence and this cycling pattern increases in duration and becomes more regular with advancing gestation. This basic rest/activity cycle evolves into recognizable distinct behavioral states only after the neural mechanisms that underlie the patterning of each variable reach the corresponding developmental stage that allow them to cycle in concert. In all mammals studied to date (i) the amount of REM sleep is initially much higher early in development than it is in later adult life; conversely, the amount of NREM sleep (and wakefulness if ever present) is lower early in development than it is in later on; (ii) patterns of REM sleep and NREM sleep brain activity continue to change postnatally, although some precocious species, humans in particular, clearly begin this process in utero; (iii) ultradian, circadian, and homeostatic sleep regulatory mechanisms undergo important modifications in the neonatal period and thereafter (see Peirano et al., 2003).

Sleep is more than the absence of wakefulness, since them both are regulated and active processes that occur at particular times within the 24-hour period. The timing of sleep and waking is regulated by two processes: (i) a circadian pacemaker located in the suprachiasmatic nuclei of the anterior hypothalamus, which is entrained to the light-dark cycle and promotes wake during an active phase of the cycle and permits sleep during a rest phase of the cycle, and (ii) a homeostatic process in which a need for sleep accumulates during waking and is dissipated or satisfied during sleep (Borbély, 1982). Since these two processes do not necessarily run during the same time period, they need a strong signal to synchronize them. The first process is affected by light, and the second one appears more like a buildup and decay of an 
unknown chemical that gets used up during the day and then is replenished when we sleep. Although these regulatory processes can operate independently, growing evidence indicates an intimate relationship between them. Finally, a third mechanism controls the ultradian alternance between NREM sleep and REM sleep, which appears to be controlled by a permanent interacting balance between brainstem aminergic and cholinergic neuronal discharges (Pace-Schott and Hobson, 2002; McCarley 2007). However, a recently described model (Lu et al., 2006) postulates that the main switching mechanisms for REM sleep involve reciprocal inhibitory interactions between mesopontine tegmentum GABA-ergic REM-off and REM-on populations (in this model the role for cholinergic and monoaminergic populations is to modulate the components of the main REM switch, but are not a part of it). These three mechanisms, in concert, produce organized sleep-wake patterns.

Several findings in adult mammals suggest that sleep is homeostatically regulated. Periods of forced waking lead to increased sleep drive, or sleepiness, with compensatory increases in the amount of sleep states in subsequent sleep (Borbély, 1982). Sleep homeostatic mechanisms undergo several important modifications during the neonatal period. The amount of waking is very low and neonates are unable to maintain consolidated bouts of waking. Short periods of sleep deprivation lead to a rapid rise in sleep pressure and produce compensatory increases in sleep time and/or intensity during recovery (Alfoldi et al., 1990; Anders and Roffwarg, 1973; Canet et al 1989; Thomas et al., 1996). Human neonates respond to selective (Anders and Roffwarg, 1973) or total sleep (Canet et al 1989; Thomas et al., 1996) deprivation with compensatory increases only in NREM sleep time.

Neonates show no evidence of circadian variations in sleep or waking states; it begins to emerge by about 5-6 weeks of age. In addition, the consolidation of sleepwaking states and their synchronization with a 24-hour day appear to be independent processes. Recent findings further support the notion that episodes of sleep and wakefulness are regulated independently, and suggest that their developmental changes can be attributed in part to increasing forebrain influences (Blumberg et al., 2005). Changes in the circadian distribution of sleep and waking episodes are also accompanied by changes within the sleep cycle itself. Young infants, unlike adults, typically begin a sleep episode in REM sleep and spend approximately equal amounts of time in each sleep state with episodes of REM sleep and NREM sleep alternating with a period of 50-60 minutes (Bes et al., 1994). Within the first weeks of life there is a rapid decrease in REM sleep during the day, accompanied by a large increase in NREM sleep at night (Coons and Guilleminault, 1982; Fagioli and Salzarulo, 1982; Navelet et al., 1982). Time spent in REM sleep declined inversely with increased wakefulness during daytime but remains fairly constant during the night (Coons and Guilleminault, 1982; Fagioli and Salzarulo, 1982; Navelet et al., 1982). Finally, changes in the nightly distribution of sleep stabilized by 3-4 months of age with a clear predominance of NREM sleep during the first third of the night and a predominance of REM in the last third (Hoppenbrouwers et al., 1982). The establishment of this adult-like distribution is marked by the changeover from REM sleep onset to the pattern of NREM sleep onset.

\section{Sleep and brain development}

A key factor in the maturation of central sensory pathways is stimulus-induced neuronal activity (Hubel and Wiesel, 1979). Depriving kittens of normal visual experience during the critical period for visual development permanently alters the physiologic response of the brain to visual stimulation. During this developmental period, synaptic connectivity in the cortex exhibits a high level of plasticity as synapses are formed and retracted, a process strongly driven by sensory activity. Brain plasticity, therefore, refers to the ability of the brain to persistently change its 
structure and function according to genetic information in response to environmental changes or to comply with the interaction between these two factors (Chen and Tonegawa, 1997). By facilitating brain plasticity, sleep would allow the organism to adapt its behaviour to the circumstances, within the constraints set by speciesspecific genetic material (Maquet et al., 2003).

The neonatal brain has brief periods of waking in which to interact and learn in the adult sense of the word. The gradual reduction in REM sleep amount with advancing age is offset by an increase in waking amount. It is clear that the waking state favors cognitive processes during early life. Transient periods of alertness can be induced or prolonged by changes in body posture and articulated visual or auditory stimuli during the first weeks of life; in both circumstances waking extension depends on a social partner. However, the essential changes in alertness that occur at 2 months of age are "the infant's ability to construct its own context of wakefulness by initiating goaldirected actions and inventing new combinations among coordinated movements" (Wolff, 1984). The timing for these changes coincides with major transitions in various aspects of the infant's neural and sensory repertoire, and the infant becomes better adapted to the extra-uterine environment.

It seems paradoxical that CNS maturational processes in the late prenatal and neonatal periods are highly active at the time that extrinsic sensory stimulation is quite limited. During these periods, a large percentage of time is spent in REM sleep, characterized by endogenous, intense, generalized neuronal firing in most areas of the brain, "it is the intensity of phasic neuronal activity during REM sleep which is high in early development and diminishes as rapid brain maturation is completed" (Mirmiran and Ariagno, 2003b). Roffwarg and coworkers were the first to propose that the primary purpose of REM sleep was to act as an inducer of CNS development in the fetus and the neonate (Roffwarg et al., 1966). Based on the early myelination of the sensory processing areas in the CNS, they further proposed that REM sleep provided endogenous stimulation to these areas. Fetal movements that are anticipatory in nature (breathing, sucking, swallowing, yawns, stretches and eye movements) occur during REM sleep.

Studies of REM sleep deprivation have provided consistent support to the role of REM sleep in brain maturation and especially on subsequent visual development (Marks et al., 1995; Oksenberg et al., 1996; Shaffery et al., 1998; Shaffery et al., 1999; Hogan et al., 2001; Shaffery et al., 2002). Kittens with normal binocular vision subjected to REM sleep deprivation during the second week of a 2-week monocular deprivation (MD) period, had further anatomically and functionally deleterious effects on the lateral geniculate nucleus (LGN) relative to MD alone (Marks et al., 1995). The effect of REM sleep deprivation in unoccluded kittens resulted in a higher magnitude impact than the one provoked by $\mathrm{MD}$, suggesting that deprivation of REM sleep during CNS development amplifies the plasticity processes generated when normal visual afferentation to central visual areas is interrupted (Oksenberg et al., 1996). Further, they demonstrated that (a) the elimination of ponto-geniculo-occipitalwave phasic activity during REM sleep (a method that preserves sleep and wake proportions as well as other REM features) similarly yielded enhanced plasticity effects in the LGN (Shaffery et al., 1999), and (b) REM sleep deprivation delayed the development of synaptic plasticity in the LGN (Hogan et al., 2001), and retarded the maturational reduction of long-term potentiation (LTP) in visual cortex of immature rats (Shaffery et al., 2002), as was the case for rats reared in darkness (Kirkwood et al., 1995).

These results emphasize that REM sleep is also an important part of visual development after birth, stimulating neurons in a fundamentally different way from that derived from visual experience (Marks et al., 1999). Moreover, since REM sleep excites neural components elsewhere in the brain -not just in the visual system- 
it also might help other areas of the brain develop. Recent studies indicate that mechanisms of synaptic plasticity, which participate in brain development and perhaps also in learning and memory processes, remain susceptible to the effects of REM sleep deprivation in the adolescent rat (Shaffery et al., 2006a; Shaffery et al., 2006b).

Although further research is needed to show the significance of these findings in humans, based on our own results showing increased retinal activity during REM sleep relative to NREM sleep in humans during early infancy (Peña et al., 1999), we suggested that greater retinal activity during this sleep state may represent a biological condition that favors the maturation of the retina (and probably other structures within the visual system). The association between retinal activity and sleep states was markedly attenuated at 4 months of post term age (Peña et al., 1999), when the quantity of wakefulness has increased (Curzi-Dascalova and Challamel, 2000; Coons and Guilleminault, 1982; Fagioli and Salzarulo, 1982; Peirano et al., 2003) and its quality improved (Wolff, 1984), paralleling the daytime decrease in the amount of REM sleep (Curzi-Dascalova and Challamel, 2000; Coons and Guilleminault, 1982; Fagioli and Salzarulo, 1982; Fagioli et al., 1989; Peirano et al., 2003).

The role of REM sleep on CNS development is further illustrated by studies indicating long-lasting behavioral changes resulting from pharmacologic REM sleep deprivation in early life (Mirmiran et al., 1983; Mirmiran, 1986; Mirmiran and Van Someran, 1993; Mirmiran, 1995). REM sleep deprived animals have a reduced brain size, hyperactivity, anxiety, attention and learning difficulties, increased voluntary alcohol consumption and reduced masculine sexual behavior. Moreover, while environmental enrichment has been shown to enhance cortical maturation, this was no longer possible in the REM sleep deprived rats (Mirmiran et al., 1983). These findings, however, should be interpreted cautiously because (i) drugs have multiple effects on the developing brain, and (ii) neonatal REM sleep suppression may not be the causal factor in adult deficits in sleep behavior (Frank and Heller, 1997). In the earlier pharmacological manipulation for REM sleep suppression more than a single neurotransmitter system was modified (Mirmiran et al., 1983; Mirmiran, 1986), while later studies used more selective pharmacologic agents that enabled the suppression of REM by changing individual neurotransmitter systems (Frank and Heller, 1997). Therefore, to what extent the outcome of the pharmacological suppression of REM in these studies is the result of interference with neurotransmitter systems rather than the loss of REM sleep per se, or even the balance between NREM sleep and wakefulness is still controversial (Mirmiran and Van Someran, 1993; Frank and Heller, 1997; Vogel et al., 1990; Vogel et al., 2000; Feng et al., 2001; Feng and Ma, 2002).

The presence of NREM sleep regulation in both neonatal rats (Alfoldi et al., 1990) and humans (Anders and Roffwarg, 1973; Thomas et al., 1996) suggests that NREM sleep may also be important for developing animals. The maturation of NREM sleep not only coincides with the formation of thalamocortical and intracortical patterns of innervation and periods of heightened synaptogenesis, but it is also associated with important processes in synaptic remodeling (Bear and Malenka, 1994; Cramer and Sur, 1995).

During NREM sleep, waking patterns of neuronal activity are reactivated, suggesting that information acquired during wakefulness is further processed during this sleep state. Buzsaki have suggested that sharp wave bursts initiated in the hippocampus during slow-wave sleep (SWS) and associated with theta and gamma oscillations may provide the mechanism by which "quanta" of information may be relayed back to the neocortex during memory consolidation (Buzsaki, 1996). His group further demonstrated a correlation between neocortical and hippocampal activity during SWS, which suggests that these hippocampal patterns are coupled selectively to the neocortical cell groups 
that participated in the triggering of the bursts (Sirota et al., 2003). It is therefore possible that NREM sleep contributes to synaptic remodeling by providing an endogenous source of repetitive, synchronized activity within specific neuronal pathways (Kavanau, 1994). Frank and coworkers have shown plasticity in the developing visual cortex induced during NREM sleep immediately following a novel experience of MD (Frank et al., 2001). Sleep, following MD, facilitated cortical changes in ocular dominance. The magnitude of plasticity was similar to that observed after continued MD, and larger than that seen after sleep deprivation in darkness, suggesting that sleep independently enables mechanisms of cortical plasticity. Since there was a positive correlation between the amount of NREM sleep and enhancement of cortical plasticity, they suggested that this sleep state, at least during the first hours after MD, plays an important role in the rapid cortical synaptic remodeling elicited by MD. This study provides support to results showing that recent experiences are strongly replayed (sleep reactivation) during SWS (Kudrimoti et al., 1999; Ji and Wilson, 2007).

\section{CONCLUDING REMARKS}

The large amounts of sleep during periods of rapid brain growth, connectivity and synaptic plasticity suggest a role for sleep in brain development. The evidence indicates that sleep states may be important for neuronal development, although the contribution of each state is likely to be different. In addition, the possible importance role of the succession of NREM sleep and REM sleep has recently been emphasized. Finally, since both sleep states also appear to promote processes dependent on synaptic remodeling, such as learning and memory (Maquet et al., 2003; Walker and Stickgold, 2006; Yoo et al., 2007; Stickgold and Walker 2007), they might influence periods of heightened synaptic plasticity and development in the maturing brain.

\section{ACKNOWLEDGEMENTS}

The authors are thankful for funding from CONICYT (Fondecyt \#1070668).

\section{REFERENCES}

ALFOLDI P, TOBLER I, BORBELY AA (1990) Sleep regulation in rats during early development. Am J Physiol 258: R634-R644

ANDERS TF, ROFFWARG HP (1973) The effects of selective interruption and deprivation of sleep in the human newborn. Dev Psychobiol 6: 79-91

ASERINSKY E, KLEITMAN N (1953) Regularly occurring periods of ocular mobility and concomitant phenomena during sleep. Science 118: 361-375

BEAR MF, MALENKA RC (1994) Synaptic plasticity: LTP and LTD. Curr Opin Neurobiol 4: 389-399

BES F, FAGIOLI I, PEIRANO P, SCHULZ H, SALZARULO $P$ (1994) Trends in EEG synchronization across non-REM sleep in infants. Sleep 17: 323-328

BLUMBERG MS, SEELKE AMH, LOWEN SB, KARLSSON KÆ (2005) Dynamics of sleep-wake cyclicity in developing rats. PNAS 102: 14860-14864

BORBELY AA (1982) A two process model of sleep regulation. Hum Neurobiol 1: 195-204

BUZSAKI G (1996) The hippocampo-neocortical dialogue. Cereb Cortex 6:81-92

CANET E, GAULTIER CL, D'ALLEST AM, DEHAN M (1989) Effects of sleep deprivation on respiratory events during sleep in healthy infants. J Appl Physiol 66: $158-163$

CHEN C, TONEGAWA S (1997) Molecular genetic analysis of synaptic plasticity, activity dependent neural development, learning, and memory in the mammalian brain. Ann Rev Neurosci 20:157-184

COONS S, GUILLEMINAULT C (1982) Development of sleep-wake patterns and non-rapid eye movement sleep stages during the first six months of life in normal infants. Pediatrics 69: 793-798

CRAMER KS, SUR M (1995) Activity dependent remodeling of connections in the mammalian visual system. Curr Opin Neurobiol 5: 106-111

CURZI-DASCALOVA L, PEIRANO P, MOREL-KAHN F (1988) Development of sleep states in normal premature and full-term newborns. Dev Psychobiol 21: 431-444

CURZI-DASCALOVA L, CHALLAMEL MJ (2000) Neurophysiological basis of sleep development. In: LOUGHLIN GM, CARROLL JL, MARCUS CL (eds) Sleep and Breathing in Children. A Developmental Approach. New York: Marcel Dekker, pp: 3-37

CZIKK MJ, TOTTEN S, HOMAN JH, WHITE SE, RICHARDSON BS (2001) Sagital sinus blood flow in the ovine fetus as a continuous measure of cerebral blood flow: relationship to behavioural state activity. Brain Res Dev Brain Res 131: 103-111

CZIKK MJ, SWEELEY JC, HOMAN JH, MILLEY JR, RICHARDSON BS (2002) Cerebral leucine uptake and protein synthesis in the near-term ovine fetus: relation to fetal behavioral state. Am J Physiol Regul Integr Comp Physiol 284: R200-R207

FAGIOLI I, SALZARULO P (1982) Sleep states development in the first year of life assessed through 24-h recording. Early Hum Dev 6: 215-228

FAGIOLI I, PEIRANO P, BES F, SALZARULO P (1989) 
Sleep in early human malnutrition. In: HORNE JA (ed) Sleep '88. Stuttgart: Gustav Fischer Verlag, pp: 58-62

FENG P, MA Y, VOGEL GW (2001) The critical window of brain development from susceptive to insusceptive. Effects of clomipramine neonatal treatment on sexual behavior. Dev Brain Res 129: 107-110

FENG P, MA Y (2002) Clomipramine suppresses postnatal REM sleep without increasing wakefulness: implications for the production of depressive behaviors. Sleep 25: 177-184

FRANK MG, HELLER HC (1997) Neonatal treatments with the serotonin uptake inhibitors clomipramine and zimelidine, but not the noradrenaline uptake inhibitor desipramine, disrupt sleep patterns in adult rats. Brain Res 768: 287-293

FRANK MG, ISSA NP, STRYKER MP (2001) Sleep enhances plasticity in the developing visual cortex. Neuron 30: 275-287

FRANK MG, BENINGTON JH (2006) The role of sleep in memory consolidation and brain plasticity: dream or reality? Neuroscientist 12:477-488

HELLER HC, FRANK MG, MORRISSETTE R (2000) The development of sleep and sleep regulation in the rat. In: BORBELY AA (ed) The Regulation of Sleep, Strasbourg: HFSP, pp: 187-195

HOGAN D, HOWARD P, ROFFWARG HP, SHAFFERY J (2001) The effects of 1 week of REM sleep deprivation on parvalbumin and calbindin immunoreactive neurons in center visual pathways of kittens. J Sleep Res 10: 285-296

HOPPENBROUWERS T, HODGMAN J, HARPER R, STERMAN M (1982) Temporal distribution of sleep states, somatic activity, and autonomic activity during the first half year of life. Sleep 5: 131-144

HUBEL DH, WIESEL TN (1979) The period of susceptibility to the physiological effects of unilateral eye closure in kittens. J Physiol (Paris) 206: 419-436

JI D, WILSON MA (2007) Coordinated memory replay in the visual cortex and hippocampus during sleep. Nature Neurosci 10: 100-107

KAVANAU JL (1994) Sleep and dynamic stabilization of neural circuitry: a review and synthesis. Behav Brain Res 63: 111-126

KIMURA K, TACHIBANA N, KOHYAMA J, TANIGUCHI M, SHIBASAKI H (2001) Tonic and phasic inhibition indices are constant among nights: new indices for evaluating the degree of the two types of motor inhibition during REM sleep. Sleep Med 2: $525-529$

KIRKWOOD A, LEE HK, BEAR MF (1995) Co-regulation of long-term potentiation and experience-dependent synaptic plasticity in visual cortex by age and experience. Nature 375: 329-331

KUDRIMOTI HS, BARNES CA, MCNAUGHTON BL (1999) Reactivation of hippocampal cell assemblies: effect of behavioral state, experience and EEG dynamics. J Neurosci 19: 4090-4101

LU J, SHERMAN D, DEVOR M, SAPER CB (2006) A putative flip-flop switch for control of REM sleep. Nature 441:589-594

MAQUET P, SMITH C, STICKGOLD R (2003) Sleep and Brain Plasticity. New York: Oxford University Press

MARKS GA, SHAFFERY JP, OKSENBERG A, SPECIALE SG, ROFFWARG HP (1995) A functional role for REM sleep in brain maturation. Behav Brain Res 69: 1-11

MARKS GA, ROFFWARG HP, SHAFFERY JP (1999) Neuronal activity in the lateral geniculate nucleus associated with ponto-geniculo-occipital waves lacks lamina specificity. Brain Res 815: 21-28
MCCARLEY RW (2007) Neurobiology of REM and NREM sleep. Sleep Med 8: 302-330

MIRMIRAN M, SCHOLTENS J, DE POLL NEV, UYLINGS HBM, DER GUGTEN JV, BOER GJ (1983) Effects of experimental suppression of active (REM) sleep during early development upon adult brain and behavior in the rat. Dev Brain Res 7: 277-286

MIRMIRAN M (1986) The importance of fetal/neonatal REM sleep. Eur J Obstet Gynecol Reprod Biol 21: $283-$ 291

MIRMIRAN M, VAN SOMERAN E (1993) The importance of REM sleep for brain maturation. J Sleep Res 2: 188-192

MIRMIRAN M (1995) The function of fetal/neonatal rapid eye movernent sleep. Behav Brain Res 69: 13-22

MIRMIRAN M, MAAS YG, ARIAGNO RL (2003a) Development of fetal and neonatal sleep and circadian rhythms. Sleep Med Rev 7: 321-334

MIRMIRAN M, ARIAGNO RL (2003b) Role of REM sleep in brain development and plasticity. In: MAQUET P, SMITH C, STICKGOLD R (eds) Sleep and Brain Plasticity. Oxford: University Press, pp: 181187

MORRISON JL, CARMICHAEL L, HOMAN J, RICHARDON BS (1997) The effects of 'sleep promoting agents' on behavioral states in the ovine fetus. Brain Res Dev Brain Res 103: 1-8

MORRISON JL, CARMICHAEL L, HOMAN J, WHITE S, RICHARDSON BS (2005) Cerebral blood flow during spontaneous and cholinergically induced behavioral states in the sheep fetus. Pediatr Res 57: 667-673

NAVELET Y, BENOIT O, BOUARD G (1982) Nocturnal sleep organization during the first months of life. Electroenceph clin Neurophysiol 54: 71-78

OKSENBERG A, SHAFFERY JP, MARKS GA, SPECIALE SG, MIHAILOFF G, ROFFWARG H (1996) Rapid eye movement sleep deprivation in kittens amplifies LGN cell-size disparity induced by monocular deprivation. Dev Brain Res 97: 51-61

PACE-SCHOTT EF, HOBSON JA (2002) The neurobiology of sleep: genetics, cellular physiology and subcortical networks. Nature Rev Neurosci 3: 591605

PEIRANO P, ALGARIN C, UAUY R (2003) Sleep-wake states and their regulatory mechanisms throughout early human development. J Pediatr 143: S70-79

PEÑA M, BIRCH D, UAUY R, PEIRANO P (1999) The effect of sleep states on electroretinographic (ERG) activity during early human development. Early Hum Dev 55: 51-62

RICHARDSON BS, CAETANO H, HOMAN J, CARMICHAEL L (1994) Regional brain blood flow in the ovine fetus during transition to the low-voltage electrocortical state. Dev Brain Res 81: 10-16

ROFFWARG HF, MUZIO J, DEMENT WC (1966) Ontogenetic development of the human sleepwakefulness cycle. Science 152: 604-619

SHAFFERY JP, OKSENBERG A, MARKS GA, SPECIALE SG, MIHAILOFF G ROFFWARG H P (1998) REM sleep deprivation in monocularly occluded kittens reduces the size of cells in LGN monocular segment. Sleep 21: 837-845

SHAFFERY JP, ROFFWARG HP, SPECIALE SG, MARKS GA (1999) Ponto-geniculo-occipital-wave suppression amplifies lateral geniculate nucleus cellsize changes in monocularly deprived kittens. Brain Res Dev Brain Res 114: 109-119

SHAFFERY JP, SINTON CM, BISSETTE G, ROFFWARG, H P, MARKS GA (2002) Rapid eye movement sleep deprivation modifies expression of 
long-term potentiation in visual cortex of immature rats. Neuroscience 110: 431-443

SHAFFERY JP, LOPEZ J, BISSETTE G, ROFFWARG HP (2006a) Rapid eye movement sleep deprivation revives a form of developmentally regulated synaptic plasticity in the visual cortex of post-critical period rats. Neurosci Lett 391: 96-101

SHAFFERY JP, LOPEZ J, BISSETTE G, ROFFWARG HP (2006b) Rapid eye movement sleep deprivation in postcritical period, adolescent rats alters the balance between inhibitory and excitatory mechanisms in visual cortex. Neurosci Lett 393: 131-135

SHIMOHIRA M, IWAKAWA Y, KOHYAMA J (2002) Rapid-eye-movement sleep in jittery infants. Early Hum Dev 66: 25-31

SILVANI A, ASTI V, BERTEOTTI C, FERRARI V, FRANZINI C, LENZI P, WILD J, GRANT DA, WALTER AM, ZOCCOLI G (2006) Sleep-dependent changes in cerebral oxygen consumption in newborn lambs. J Sleep Res 15: 206-211

SIROTA A, CSICSVARI J, BUHL D, BUZSAKI G (2003) Communication between neocortex and hippocampus during sleep in rodents. Proc Natl Acad Sci 100:20652069

STERIADE M (2006) Grouping of brain rhythms in corticothalamic systems. Neuroscience 137: 1087-1106
STICKGOLD R, WALKER MP (2007) Sleep-dependent memory consolidation and reconsolidation. Sleep Med 8: $331-343$

THOMAS DA, POOLE K, MCARDLE EK, GOODENOUGH PC, THOMPSON J, BEARDSMORE CS SIMPSON H (1996) The effect of sleep deprivation on sleep states, breathing events, peripheral chemoresponsiveness and arousal propensity in healthy 3 month old infants. Eur Respir J 9: 932-938

VOGEL G, NEIL D, HAGLER M, KORS D, HARTLEY P (1990) A new animal model of endogenous depression: a summary of present findings. Neurosci Biobehav Rev 14: $85-91$

VOGEL GW, FENG P, KINNEY GG (2000) Ontogeny of REM sleep in rats: possible implications for endogenous depression. Physiol Behav 68: 453-461

WALKER MP, STICKGOLD R (2006) Sleep, memory, and plasticity. Annu Rev Psychol 57: 139-166

WOLFF PH (1984) Discontinuous changes in human wakefulness around the end of the second month of life: a developmental perspective. In: PRECHTL, HFR (ed) Continuity of Neural Functions from Prenatal to Postnatal Life. Oxford: Blackwell, pp: 144-158

YOO SS, HU PT, GUJAR N, JOLESZ FA, WALKER MP (2007) A deficit in the ability to form new human memories without sleep. Nat Neurosci 10: 385-392 